\title{
REFORMA AGRÁRIA, CAOS URBANO, AGRONEGÓCIO E PANDEMIA
}

\section{Agrarian reform, urban chaos, agribusiness and pandemic}

\author{
Paulo Roberto Raposo Alentejano ${ }^{1}$ \\ Professor Associado do Departamento de Geografia da FFP-UERJ \\ paulinhochinelo@gmail.com
}

Artigo enviado para publicação em 17/04/2020 e aceito em 27/04/2020

DOI: $10.12957 /$ tamoios.2020.50242

\begin{abstract}
Resumo
O sistema agroalimentar dominante, baseado em extensas monoculturas e criação de animais em larga escala, tem contribuído para multiplicar epidemias, em função da destruição de ambientais florestais e da proliferação de pragas e novos patógenos. As grandes metrópoles são espaços cada vez mais caóticos e favoráveis à disseminação das epidemias. Reestruturar os sistemas agroalimentar e urbano passa pela realização de uma reforma agrária agroecológica que redistribua a terra concentrada nos latifúndios e promova a produção descentralizada de alimentos saudáveis, como tem sido reivindicado pelos movimentos sociais do campo, em especial o MST.
\end{abstract}

Palavras-chave: reforma agrária; agroecologia; agronegócio; Covid-19.

\begin{abstract}
The dominant agri-food system, based on extensive monocultures and large-scale animal husbandry, has contributed to multiply epidemics, due to the destruction of forest environment and the proliferation of pests and new pathogens. The large metropolises are increasingly chaotic spaces and favorable to the spread of epidemics. To restructure the agri-food and urban systems involves the realization of an agroecological agrarian reform that redistributes the land concentrated in the latifundia and promotes the decentralized production of healthy foods, as has been claimed by rural social movements, especially the MST.
\end{abstract}

Keywords: agrarian reform; agroecology; agribusiness; Covid-19. 
Em pequeno texto do longínquo ano de 1998, denominado "Reforma agrária para resolver a crise urbana" (ALENTEJANO, 1998), argumentava sobre o caos urbano característico das nossas grandes metrópoles - Rio e São Paulo em especial - e sobre a contribuição que a reforma agrária poderia dar para a reorganização territorial da sociedade brasileira e a construção de uma sociedade mais justa, democrática e ambientalmente saudável. Nestes tempos de pandemia e enclausuramento foi inevitável lembrar deste texto.

O centro do argumento à época era a questão do combate ao desemprego e à miséria característicos de nossas metrópoles, diante da

incapacidade da sociedade urbano-industrial, calcada nas modernas tecnologias da informática e da robótica, incluir o enorme contingente de trabalhadores que habitam hoje as periferias das cidades. (ALENTEJANO, 1998: 2)

Argumentava então que "uma ampla reforma agrária poderia ser capaz de reverter este quadro, possibilitando moradia, trabalho e cidadania a essa massa de explorados e excluídos" (ALENTEJANO, 1998: 2).E definia essa reforma agrária como a constituição de comunidades rurais onde se articulariam atividades agrícolas e nãoagrícolas ocupando os milhões de hectares sob o controle do latifúndio:

\begin{abstract}
a solução para a crise que se abate sobre as cidades brasileiras e o caminho para construir uma sociedade mais justa e democrática passam pelo aproveitamento do imenso estoque de terras inaproveitadas e mal aproveitadas pelos latifundiários brasileiros (e estrangeiros) para o assentamento massivo de trabalhadores rurais e urbanos, oferecendo a estes infra-estrutura adequada, apoio à produção agrícola e não-agrícola e condições para o livre exercício de sua cidadania. Isto seria o princípio de um processo de revolução da nossa organização social e territorial. (ALENTEJANO, 1998: 4)
\end{abstract}

Acredito que o argumento continua plenamente válido, afinal de lá pra cá o caos urbano nas nossas metrópoles só se ampliou, assim como o desemprego e a miséria (embora na década de 2000 tenha havido redução do desemprego e da miséria, voltaram a crescer na atual década). Também continua válido em relação à persistência do controle do latifúndio sobre as terras brasileiras e seu baixo índice de aproveitamento, em que pese mudanças no campo resultantes da expansão do agronegócio "associação do grande capital agroindustrial com a grande propriedade fundiária, sob patrocínio fiscal, financeiro e patrimonial do estado" (Delgado, 2006:1).E acrescentamos, com a sustentação ideológica da grande imprensa empresarial, que todos os dias desde 2016 nos bombardeia com os dizeres de que"Agro é tech, Agro é pop, Agro é tudo!"

Mas a atual crise gerada pela pandemia da Covid-19 permite ir além do que afirmei em 1998 e articular esse argumento com a crítica ao modelo agroalimentar dominante.

Inúmeros estudos têm apontado para a insustentabilidade do atual sistema agroalimentar baseado na produção em larga escala de um pequeno número de espécies vegetais e animais, sob a forma de extensas monoculturas e produção de animais confinados em "fábricas de proteínas".

Segundo Altieri \& Nicholls (2020: 1/2), os grandes monocultivos ocupam $80 \%$ dos 1.500 milhões de hectares dedicados à agricultura em todo o mundo e para controlar as pragas que se multiplicam nestes campos com baixa diversidade ecológica e alta homogeneidade genética são aplicados 2.300 milhões de $\mathrm{kg}$ de pesticidas por ano, o que 
resulta no envenenamento de 26 milhões de pessoas por agrotóxicos no mundo todo ano.

Silvia Ribeiro, por sua vez, afirma que há três causas concomitantes e complementares que produziram a proliferação das principais epidemias das últimas décadas, como a gripe aviária, a gripe suína e a própria pandemia do novo coronavírus:

A principal é criação industrial e extensiva de animais, principalmente frangos, perus, porcos e vacas. A isto soma-se o contexto geral da agricultura industrial, na qual $75 \%$ da terra agrícola de todo o planeta é utilizada para a criação de animais em massa, principalmente para criação de pastos com essa finalidade. A terceira é o crescimento descontrolado da mancha urbana e das indústrias que a alimentam e que por ela subsistem. (RIBEIRO, 2020: 1)

A aglomeração de milhares de animais confinados em pequenos espaços é uma fonte inesgotável de multiplicação de doenças, algumas das quais permanecem apenas circulando entre estes, mas outras acabam, através de mutações, saltando dos animais para os seres humanos, como também argumentam Altieri \& Nicholls (2020: 2):

\begin{abstract}
As grandes propriedades que tem dezenas de milhares de aves ou milhares de porcos, em nome de uma produção eficiente de proteínas, criam uma oportunidade para que os vírus como a influenza sofram mutação e se propaguem. Mais de 50 milhões de galinhas e perus nos Estados Unidos morreram pela gripe aviária. As práticas nestas operações industriais (confinamento, exposição respiratória a altas concentrações de amoníaco, sulfeto de hidrogênio, etc. que emanam dos dejetos) não somente deixam os animais mais susceptíveis as infecções virais, como podem proporcionar as condições pelas quais os patógenos podem evoluir a tipos de vírus mais contagiosos e infecciosos.
\end{abstract}

Por outro lado, o crescimento deste tipo de criação animal exige o desmatamento de áreas cada vez mais extensas para a expansão do plantio de culturas como soja e milho que servem de base para a produção de ração para a alimentação animal. Estas culturas, por sua vez têm seus próprios impactos, uma vez que são produzidas com uso intensivo de derivados de combustíveis fósseis, agrotóxicos e água (70\% da água doce é usada para irrigação). Este modelo agroalimentar também torna mais pobre a dieta alimentar dos povos.

Outra consequência sobre a saúde pública da intensificação da agricultura tem sido a diminuição da diversidade de cultivos nas paisagens agrícolas. Apesar dos seres humanos poderem comer mais de 2.500 espécies de plantas, a dieta da maioria das pessoas é composta por três culturas principais, como trigo, arroz e milho, que fornecem mais de $50 \%$ das calorias consumidas em nível mundial. (ALTIERI \& NICHOLLS, 2020: 3)

A expansão dessas grandes monoculturas se faz, muitas vezes, deslocando outras culturas e criações para novas áreas, promovendo o desmatamento de florestas que até então era habitadas por populações indígenas e camponesas que acabam sendo expulsas dessas áreas.

são a causa do desmatamento e da destruição de habitats naturais em todo o mundo, fato que também implica a expulsão das comunidades indígenas e camponesas que vivem nessas áreas. Segundo a Organização das Nações Unidas para a Alimentação e a Agricultura (FAO), mundialmente, a expansão da fronteira agropecuária é responsável por $70 \%$ do desmatamento, mas em 
países como o Brasil, esta expansão é responsável por $80 \%$ do desmatamento. (RIBEIRO, 2020: 1)

O avanço do desmatamento, por sua vez, leva animais silvestres que antes se encontravam nas florestas a se deslocar para outras áreas, inclusive urbanas, transformando-se também em vetores da disseminação de doenças. Segundo Altieri \& Nicholls (2020: 3) "um mero aumento de 4\% no desmatamento na Amazônia aumentou a incidência de malária em quase 50\%".

Os vírus podem passar de uma espécie a outra e embora possam se originar em espécies silvestres de aves, morcegos e outras, é a destruição dos habitats naturais que os empurra para fora de suas áreas, onde as cepas dos vírus estavam controladas dentro de sua própria população. Dali passam às áreas rurais e depois às cidades. (RIBEIRO, 2020: 2)

Cidades estas, principalmente as maiores, onde parte crescente da alimentação é fornecida pelas mesmas agroindústrias que, como vimos acima, são fábricas de doenças. Além de produzirem comidas que provocam outros problemas graves de saúde:

segundo os dados da Organização Mundial da Saúde, $72 \%$ das mortes no mundo são causadas por doenças não transmissíveis, várias delas diretamente relacionadas diretamente ao sistema alimentar do agronegócio, como doenças cardíacas, hipertensão, diabetes, obesidade, câncer do aparelho digestivo, má nutrição. (RIBEIRO, 2020: 2)

Altieri \& Nicholls chamam atenção também para o fato de que o sistema alimentar globalizado, no qual alimentos são transportados a longas distâncias entre países e até continentes, fragiliza os países num contexto de restrição de mobilidade como o de uma pandemia. E que o acesso a alimentos é particularmente crítico para cidades com mais de 5 milhões de pessoas que "precisam importar não menos que 2.000 toneladas de alimentos por dia, percorrendo uma média de 1.000 quilômetros" (Altieri \& Nicholls, 2020: 4).

Torna-se, portanto, urgente reverter este modelo agroalimentar, em direção a uma agricultura descentralizada e agroecológica, o que só é possível como uma ampla reforma agrária que multiplique as pequenas unidades de produção de alimentos saudáveis.Como diz o sociólogo argentino Miguel Teubal:

...la lucha por la tierra y la reforma agraria hacia fines del siglo XX, comienzos del nuevo milenio, constituye una lucha contra el modelo de agricultura industrial o agroalimentario, impulsado por estas transnacionales que dominan tecnologías de punta, canales de comercialización de alimentos, grandes industrias alimentarias, así como también la producción de semillas y productos transgénicos. Surge en consecuencia que la lucha por la tierra es también una lucha en contra de un nuevo establishment surgido en escala mundial que incide sobre múltiples aspectos que atañen a la tierra y al sistema agroalimentario en su conjunto. Es, asimismo, una lucha en contra de toda una cultura impulsada por ese establishment vinculado al mercado y a la mercantilización de la vida misma. (TEUBAL, 2009: 226/227)

A construção de uma reforma agrária agroecológica tem sido colocada como pauta central pelo Movimento dos Trabalhadores Rurais Sem Terra (MST) e outros movimentos sociais do campo. Trata-se não apenas de mudar o padrão técnico dominante com a rejeição aos agrotóxicos, mas de construir outras práticas produtivas, outras formas de comercialização, outras relações de trabalho, outras relações 
sociedade-natureza que superem a fratura metabólica instaurada pelo capital ao separar não apenas os trabalhadores dos meios de produção, mas homens e mulheres da natureza (MARX, 1989).

A reforma agrária agroecológica implica também rever as relações campo-cidade e a divisão internacional do trabalho, de forma a reverter a falha metabólica.

Para Marx, a falha metabólica associada no nível social com a divisão antagônica entre cidade e campo também era evidente em nível mais global: colônias inteiras se viam roubadas da sua terra, recurso e solo para sustentar a industrialização dos países colonizadores. (FOSTER, 2005: 230)

Se no século XIX essa relação destrutiva se dava entre países colonizadores e colônias, hoje se dá entre os países centrais e periféricos. A América Latina, em especial, é hoje o continente onde mais se expandem as grandes monoculturas de grãos, como soja e milho, principalmente nos países do Cone Sul, Argentina, Uruguai, Paraguai e Brasil. Este processo se intensificou ainda mais nas últimas duas décadas com o consenso das commodities (SVAMPA, 2017), quando em quase todos os países da América Latina se desenvolveu uma espécie de consenso político e ideológico de que a única via legítima ou possível para o desenvolvimento seria através da exploração intensiva e em grande escala de recursos naturais para a produção de produtos primários, o que também foi denominado de neoextrativismo (GUDYNAS, 2015) e reconversão neocolonial (SAMPAIO JR., 2012).

Reverter esse processo através da reforma agrária agroecológica permitiria produzir localmente alimentos saudáveis e ao mesmo tempo combater a difusão das epidemias que têm assolado o mundo:

\begin{abstract}
A agroecologia propõe restaurar as paisagens que circundam as propriedades rurais, o que enriquece a matriz ecológica e seus serviços, como controle natural de pragas, conservação do solo e da água, etc., mas também cria "quebra-fogos ecológicos" que podem ajudar a impedir que patógenos escapem de seus habitats. (ALTIERI \& NICHOLLS, 2020: 4)
\end{abstract}

Altieri \& Nicholls (2020: 5) destacam também a importância do papel dos consumidores que devem compreender que comer é um ato político e ecológico. E por isso devem apoiar o desenvolvimento de mercados locais e regionais regidos pelos princípios da economia solidária.

É este o sentido de ações desenvolvidas pelo MST, como a multiplicação das feiras da reforma agrária nos estados e a realização da Feira Nacional da Reforma Agrária, em São Paulo, já na sua terceira edição. Espaços nos quais não apenas se vende diretamente a produção dos assentados, mas também se debate a reforma agrária e a agroecologia e se manifesta a cultura popular. Assim como o fazem os Armazéns do Campo abertos em São Paulo, Belo Horizonte, Rio de Janeiro, Recife, Caruaru, Porto Alegre, São Luís... Espaços onde os alimentos saudáveis se misturam à música, à poesia e à política.

Também nas escolas dos assentamentos a agroecologia tem se tornado referência pedagógica para a Educação do Campo, isto é, a educação pensada para e a partir das populações do campo, suas lutas, sua cultura, suas formas de organização social. A agroecologia tem sido inserida nos currículos das escolas do campo na forma de disciplina específica, como no caso do estado da Bahia ou como conteúdo articulador, como nas experiências das escolas itinerantes dos acampamentos no estado do Paraná, entre outros exemplos.

Foi esse, igualmente, o recado dado pelas crianças no I Encontro Nacional das Crianças Sem Terrinha, realizado em julho de 2018, que reuniu em Brasília mais de 1.000 
crianças de 24 estados brasileiros para, através de jogos, brincadeiras, oficinas, música, teatro e poesia, debater reforma agrária, alimentação saudável e direito à educação, saúde e cultura para as crianças do campo. Sob o lema "Sem Terrinha em movimento: brincar, sorrir, lutar por reforma agrária popular", as crianças realizaram ainda um passeio/manifestação na Esplanada dos Ministérios e na Praça dos Três Poderes, onde expressaram sua inconformidade com o fechamento de escolas no campo e exigiram reforma agrária e alimentação saudável. Uma das principais cantigas que ecoou pelos inóspitos e insensíveis espaços da capital federal na marcha dos sem terrinha em 2018: "Sou Sem Terrinha do MST/Acordo todo dia pra lutar você vai ver/Por terra, por escola, saúde, educação/Desse meu direito eu não abro mão".

Assim, o MST tem renovado o debate sobre a reforma agrária no Brasil, articulando-o com educação, cultura, ecologia, afinal, como nos lembra Miguel Carter, é um debate que transcende o mundo rural:

O debate em vigor no Brasil sobre a reforma agrária toca assuntos que ultrapassam a questão fundiária e o desenvolvimento rural. Os assuntos em pauta levantam problemas mais profundos da sociedade brasileira. $\mathrm{Na}$ alvorada do século XXI, a reforma agrária continua sendo parte de uma conversação complexa e contenciosa sobre o futuro do Brasil - suas promessas e necessidades, seus temores e sonhos. (CARTER, 2010: 71).

Portanto, é preciso articular movimentos sociais rurais e urbanos para a construção de uma reforma agrária agroecológica que pode e deve ser parte de uma estratégia política destinada a combater ao mesmo tempo a desigualdade, a miséria, o desemprego, o caos urbano e a(s) pandemia(s), contribuindo para superar o atual modelo agroalimentar e construir outra sociedade onde a vida valha mais do que os interesses do capital.

Nossas grandes metrópoles são espaços ingovernáveis, marcadas por profundas desigualdades, com trânsito caótico, falta de saneamento, ilhas de calor e poluição, ambientes mais do que favoráveis à disseminação de epidemias e pandemias ligadas aos mais diferentes agentes infectocontagiosos.

A desconcentração espacial da população brasileira através de uma ampla reforma agrária agroecológica permitiria ao mesmo tempo combater todas essas mazelas. Terra para isso não falta, afinal há no Brasil 247,7milhões de hectares sob o controle do latifúndio, dos quais 175,9 milhões de terras improdutivas. Há ainda no país 61,4 milhões de hectares dedicados à produção de cana, milho e soja, a maioria na lógica agroindustrial.Por outro lado, a área plantada com alimentos básicos (arroz, feijão e mandioca) diminuiu 5 milhões de hectares nos últimos 30 anos, indicando como o sistema agroalimentar dominante fragiliza a soberania alimentar dos países, pois o espaço agrário passa a ser destinado não ao que interessa à população dos países, mas aos interesses das grandes corporações transnacionais que controlam o setor.

Urge reverter esse cenário e só uma reforma agrária agroecológica pode fazê-lo. Antes que se ampliem ainda mais a fome, a miséria e as doenças geradas por esse insano modelo agroalimentar dominado pelas grandes corporações do agronegócio. 


\section{Nota}

1 - É membro dos Programas de Pós-Graduação em Geografia da FFP/UERJ e em Desenvolvimento Territorial da América Latina e Caribe da Universidade Estadual Paulista - TerritoriAL/Unesp em parceria com a Escola Nacional Florestan Fernandes. Coordenador do Grupo de Estudos, Pesquisa e Extensão em Geografia Agrária (GeoAgraria). Integrante do Grupo de Trabalho de Assuntos Agrários da Associação dos Geógrafos Brasileiros das Seções Rio de Janeiro e Niterói.

\section{Referências Bibliográficas}

ALENTEJANO, Paulo. Reforma agrária para resolver a crise urbana. AGB em Debate. AGB, 1998.

ALTIERI, Miguel A. \&NICHOLLS, Clara I. La agroecología en tiempos del COVID19. Califórnia, 2020.(disponível em https://www.alainet.org/)

CARTER, Miguel. Desigualdade social, democracia e reforma agrária no Brasil. In CARTER, Miguel. (org.) Combatendo a desigualdade social: o MST e a reforma agrária no Brasil. São Paulo: Editora Unesp, 2010.

DELGADO, Guilherme Costa. O que significa agronegócio no Brasil. Brasília: IPEA, 2006.

FOSTER, John Bellamy. A ecologia de Marx: materialismo e natureza. Rio de Janeiro: Civilização Brasileira, 2005.

GUDYNAS, Eduardo. Extractivismos - ecología, economía y política de un modo de entender eldesarrollo y lanaturaleza. Cochabamba: CEDIB, 2015.

MARX, Karl. O capital. Rio de Janeiro: Bertrand Brasil, 1989.

RIBEIRO, Silvia. Os latifundiários da pandemia. ETC,México: 2020. (disponível em https://www.alainet.org/)

SAMPAIO Jr. de Arruda. Desenvolvimentismo e neodesenvolvimentismo: tragédia e farsa. Serviço Social e Sociedade. São Paulo, n. 112, p. 672-688, out/dez, 2012.

SVAMPA, Maristella. Del cambio de época al fin de ciclo: gobiernos progresistas, extractivismo y movimientos sociales en América Latina. Buenos Aires: Edhasa, 2017.

TEUBAL, Miguel. La lucha por la tierra en América Latina. In GIARRACA, N. \&TEUBAL, M. (coords.). La tierra es nuestra, tuya y de aquél - las disputas por el territorio en América Latina. Buenos Aires: Antropofagia, 2009. 